\title{
Optimisation of Synthetic Medium Composition for Levorin Biosynthesis by Streptomyces levoris $99 / 23$ and Investigation of its Accumulation Dynamics Using Mathematical Modelling Methods
}

\author{
VESELIN S. STANCHEV ${ }^{1 *}$, LUBKA Y. KOZHUHAROVA², BORIANA Y. ZHEKOVA ${ }^{3}$ \\ and VELIZAR K. GOCHEV ${ }^{4}$

\footnotetext{
${ }^{1}$ Department of Automatics, Information and Control Systems, University of Food Technologies, Plovdiv, Bulgaria

${ }^{2}$ Department of Biotechnology, University of Food Technologies, Plovdiv, Bulgaria

${ }^{3}$ Department of Biochemistry and Molecular Biology, University of Food Technologies, Plovdiv, Bulgaria

${ }^{4}$ Department of Biochemistry and Microbiology, P. Hilendarski University, Plovdiv, Bulgaria
}

Received 3 April 2010, accepted 25 May 2010

\begin{abstract}
The composition of a synthetic culture medium for levorin biosynthesis by Streptomyces levoris 99/23 was optimised using mathematical modelling methods. The optimal concentrations of the medium components were established by means of an optimum composition design at three factor variation levels. An adequate regression model was obtained. Levorin biosynthesis by Streptomyces levoris 99/23 in the optimised synthetic medium was over $38 \%$ higher than in the initial medium. The antibiotic biosynthesis dynamics in the optimised culture medium was studied by means of a non-linear differential equation system. The resultant model was valid.
\end{abstract}

K e y w ords: Streptomyces levoris 99/23, biosynthesis dynamics, mathematical modelling, optimisation of levorin biosynthesis

\section{Introduction}

Levorin is an antifungal preparation widely used in medicine. The antibiotic biosynthesis mechanism and the characteristics of its producers in a physiological aspect are studied mainly by means of synthetic culture media (Belousova et al., 1970; Jakovleva, 1980). These media have strain-specific compositions which are determined experimentally. Culture medium optimisation in a quantitative and qualitative aspect using mathematical modelling methods is insufficiently studied. Orthogonal Latin rectangles were used by Jakovleva (1980), and linear models were applied by Gotchev et al. (2002). There are individual reports on biosynthesis description using neural networks (XianFa et al., 2000). From a practical point of view, however, they are more suitable for process control rather than investigation since kinetic constant values are most often hidden either in the architecture or in the weight coefficients of the neural network.

This paper aimed to determine the optimal concentrations of the synthetic culture medium components for levorin biosynthesis by Streptomyces levoris 99/23 and study levorin accumulation dynamics using mathematical modelling methods.

\section{Experimental}

Materials and Methods

Microorganism. A Streptomyces levoris 99/23 strain stored in a lyophilised form in the Biotechnology Department's collection at UFT was used as a levorin producer (Kozhuharova et al., 2002). The culture was maintained on a medium described by Kozhuharova et al. (2008).

Media and cultivation conditions. The initial nutrient medium for S. levoris 99/23 cultivation, which was subject to optimization, had the following composition (\%): glucose 1.5; starch 2; $\left(\mathrm{NH}_{4}\right)_{2} \mathrm{SO}_{4} 0.6$; $\mathrm{KH}_{2} \mathrm{PO}_{4} 0.005 ; \mathrm{KCl} 0.1 ; \mathrm{MgSO}_{4} 0.25 ; \mathrm{CaCO}_{3} 0.3$. After $\mathrm{pH}$ adjustment to 7.2 , and sterilization at $121^{\circ} \mathrm{C}$ for $30 \mathrm{~min}$, the nutrient medium was inoculated with

* Corresponding author: V.S. Stanchev, 26 Maritza Boulevard, 4002 Plovdiv, Bulgaria; phone: (+359) 32603898; fax: (+359) 32644102; e-mail: vsstanchev@abv.bg 
$2 \%(\mathrm{v} / \mathrm{v})$ spore inoculum containing $2.10^{9} \mathrm{cfu} / \mathrm{ml}$. Strain cultivation and levorin biosynthesis were carried out in $500 \mathrm{ml}$ Erlenmayer flasks containing $50 \mathrm{ml}$ of each nutrient medium at a temperature of $28^{\circ} \mathrm{C}$, on a rotary shaker $\left(220 \mathrm{~min}^{-1}\right)$ for $96 \mathrm{~h}$.

Mathematical modelling. The optimal concentrations of medium components were determined using optimal composition design with three variation levels of the factors (Koleva et al., 2005; Mason et al., 2003). Such an approach enables generation of nonlinear regression models with a minimum number of experiments:

$$
Y_{\text {mod }}=b_{0}+\sum_{i=1}^{k} b_{i} \cdot x_{i}+\sum_{i=1}^{k} b_{i i} \cdot x_{i}^{2}+\sum_{i=1}^{k-1} \sum_{j=2}^{k} b_{i j} \cdot x_{j} \cdot x_{j}
$$

where: $Y_{\text {mod }}$ is the predicted response, $b_{i}, b_{i j}$ and $b_{i i}$ are coefficients accounting for the effect of each factor $\left(x_{i}\right)$, of their interrelations $\left(x_{i} \cdot x_{j}\right)$, and those to the square of two $\left(x_{i}^{2}\right)$ respectively, and $k$ is the number of factors.

The experimental data statistical processing and the results analysis were performed using Anova (Microsoft Excel 2003).

The process dynamics was studied by submerged cultivation of the strain in the optimised culture medium. The input parameter values were approximated by third order spline functions (Mathews and Fink, 2001). The calculation and optimisation procedures were performed within the Eureka software environment (The Software Eureka 2000). The graphic presentation was based on Microsoft Excel 2003 and Sigma Plot 9.0.

Assays. Levorin concentration in the culture medium was analysed according to the spectrophotometric method suggested by Bob et al. (1978) and expressed in $\mathrm{mg} / \mathrm{ml}$. One antibiotic activity unit (IU) corresponds to $0.04 \mu \mathrm{g}$ of levorin (Bolshakova et al., 1989). Reducing sugars (substrate) concentration was determined by the dinitrosalicylic acid method (Miller, 1959). The biomass quantity was determined after drying at $105^{\circ} \mathrm{C}$ to constant weight. $\mathrm{pH}$ was measured potentiometrically.

\section{Results and Discussion}

Following a series of single-factor experiments, the variation interval for the basic culture medium components was determined. The real and coded values of the independent variables are shown in Table I. The remaining constituents were fixed at the following levels (\%): $\mathrm{KCl} 0.1 ; \mathrm{MgSO}_{4} 0.25 ; \mathrm{CaCO}_{3} 0.3$.

The experimental data was formed as the mean value of the results of six parallel experiments. The design matrix, the experimental results $\left(Y_{\text {exp }}\right)$ and model values $\left(Y_{\text {mod }}\right)$ obtained by equation (2) are presented in Table II.
Table I

Real and coded values of independent variables

\begin{tabular}{|l|l|c|l|}
\hline \multirow{2}{*}{ Factor (\%) } & \multicolumn{3}{|c|}{ Coded value } \\
\cline { 2 - 4 } & -1 & 0 & +1 \\
\hline $\mathrm{X}_{1}:$ glucose & 1.0 & 1.5 & 2.0 \\
\hline $\mathrm{X}_{2}:$ starch & 1.0 & 2.0 & 3.0 \\
\hline $\mathrm{X}_{3}:\left(\mathrm{NH}_{4}\right)_{2} \mathrm{SO}_{4}$ & 0.4 & 0.6 & 0.8 \\
\hline $\mathrm{X}_{4}: \mathrm{KH}_{2} \mathrm{PO}_{4}$ & 0.001 & 0.0055 & 0.01 \\
\hline
\end{tabular}

Table II

Optimum composition design for 4 factors and three levels of their variation

\begin{tabular}{|r|r|r|r|r|c|c|}
\hline No & $\mathrm{X}_{1}$ & $\mathrm{X}_{2}$ & $\mathrm{X}_{3}$ & $\mathrm{X}_{4}$ & $Y_{\text {exp }}(\mathrm{mg} / \mathrm{ml})$ & $Y_{\text {mod }}(\mathrm{mg} / \mathrm{ml})$ \\
\hline 1 & 1 & 1 & 1 & 1 & 0.667 & 0.597 \\
\hline 2 & 1 & 1 & 1 & -1 & 0.724 & 0.748 \\
\hline 3 & 1 & 1 & -1 & 1 & 0.785 & 0.737 \\
\hline 4 & 1 & 1 & -1 & -1 & 0.576 & 0.603 \\
\hline 5 & 1 & -1 & 1 & 1 & 1.242 & 1.135 \\
\hline 6 & 1 & -1 & 1 & -1 & 0.581 & 0.581 \\
\hline 7 & 1 & -1 & -1 & 1 & 0.860 & 0.806 \\
\hline 8 & 1 & -1 & -1 & -1 & 0.529 & 0.537 \\
\hline 9 & -1 & 1 & 1 & 1 & 0.718 & 0.781 \\
\hline 10 & -1 & 1 & 1 & -1 & 0.726 & 0.751 \\
\hline 11 & -1 & 1 & -1 & 1 & 0.851 & 0.921 \\
\hline 12 & -1 & 1 & -1 & -1 & 0.573 & 0.605 \\
\hline 13 & -1 & -1 & 1 & 1 & 0.894 & 0.950 \\
\hline 14 & -1 & -1 & 1 & -1 & 0.572 & 0.578 \\
\hline 15 & -1 & -1 & -1 & 1 & 0.588 & 0.622 \\
\hline 16 & -1 & -1 & -1 & -1 & 0.527 & 0.535 \\
\hline 17 & -1 & 0 & 0 & 0 & 0.592 & 0.693 \\
\hline 18 & 1 & 0 & 0 & 0 & 0.691 & 0.693 \\
\hline 19 & 0 & -1 & 0 & 0 & 0.903 & 0.820 \\
\hline 20 & 0 & 1 & 0 & 0 & 0.812 & 0.820 \\
\hline 21 & 0 & 0 & -1 & 0 & 0.714 & 0.739 \\
\hline 22 & 0 & 0 & 1 & 0 & 0.700 & 0.646 \\
\hline 23 & 0 & 0 & 0 & -1 & 0.635 & 0.691 \\
\hline 24 & 0 & 0 & 0 & 1 & 0.620 & 0.590 \\
\hline
\end{tabular}

The analytical expression of the regression equation obtained is:

$$
\begin{aligned}
Y_{\text {mod }} & =0.6928+0.0472 \cdot \mathrm{X}_{3}+0.1007 \cdot \mathrm{X}_{4}-0.0467 \cdot \mathrm{X}_{1} \cdot \mathrm{X}_{2} \\
& -0.0459 \cdot \mathrm{X}_{2} \cdot \mathrm{X}_{3}-0.0595 \cdot \mathrm{X}_{2} \cdot \mathrm{X}_{4}-0.0454 \cdot \mathrm{X}_{1} \cdot \mathrm{X}_{2} \cdot \mathrm{X}_{4} \\
& -0.0714 \cdot \mathrm{X}_{2} \cdot \mathrm{X}_{3} \cdot \mathrm{X}_{4}+0.1276 \cdot \mathrm{X}_{2}^{2}-0.1024 . \mathrm{X}_{4}^{2}
\end{aligned}
$$

The model was adequate at confidence level $\alpha=0.05$ and degrees of freedom $v=9$ (Table III).

The analysis of (2) revealed several considerations.

The two carbon sources $\left(\mathrm{X}_{1}, \mathrm{X}_{2}\right)$ were not present on their own in the model but the coefficient before $\mathrm{X}_{2}^{2}$ in (2) had higher positive value. Its effect in $Y_{\bmod }$ in relation to $b_{0}$ was $18.4 \%$. This showed that S. levoris $99 / 23$ preferred a carbon source with a relatively high molecular mass. On the other hand, $\mathrm{X}_{1}$ 
Table III

Statistical analysis results according to Anova

\begin{tabular}{|l|c|c|c|c|c|}
\hline Parameter & Df & SS & MS & F & Significance F \\
\hline Regression & 9 & 0.5176539 & 0.057517098 & 10.21185 & $9.32311 \mathrm{E}-05$ \\
\hline Residual & 14 & 0.0788534 & 0.005632389 & & \\
\hline Total & 23 & 0.5965073 & & & \\
\hline
\end{tabular}

Df - degree of freedom; SS - sum square; MS - mean square; F - Fisher coefficient

participated in two terms of (2) with total weight of $13.3 \%$ in relation to $b_{0}$. Since the effect of both factors in $Y_{\text {mod }}$ is commensurate, there is sufficient ground to believe that they are in optimum correlation ensuring the absolute extremum of (2).

$\mathrm{X}_{4}$ had a pronounced individual influence in the model $\left(15 \%\right.$, which is comparable to that of $\left.\mathrm{X}_{2}^{2}\right)$. $\mathrm{KH}_{2} \mathrm{PO}_{4}$ was a source of phosphorus, an important element for the $S$. levoris growth and levorin biosynthesis regulator. In this respect, the results obtained are in agreement with the theoretical formulations and data reported by other authors (Belousova et al., 1970).

The nitrogen source can be seen as having no significant effect on levorin biosynthesis.

The conditions maximising (2) were found by means of a gradient optimisation method (The Software Eureka 2000):

$$
\begin{aligned}
Y_{\bmod }^{\max }= & 1.135 \mathrm{mg} / \mathrm{ml}, \text { at: } \mathrm{X}_{1}=+1 ; \mathrm{X}_{2}=-1 ; \\
& \mathrm{X}_{3}=+1 ; \mathrm{X}_{4}=+1
\end{aligned}
$$

The response function (2), in graphic form, with variation of $X_{1}$ and $X_{2}$ within the limits set in Table I and optimum values of $\mathrm{X}_{3}$ and $\mathrm{X}_{4}(+1)$, is presented on Fig. 1.

The hypothesis of equality of the mathematical expectation of the experiment results $Y_{\text {exp }}^{\max }$ under the optimal conditions with that of the predicted $Y_{\bmod }^{\max }=1.135$ was checked (Mason et al., 2003). The values $(\mathrm{mg} / \mathrm{ml})$ were as follows: $Y_{\text {exp }, 1}^{\max }=1.20$; $Y_{\text {exp }, 2}^{\max }=1.22 ; Y_{\text {exp }, 3}^{\max }=1.16 ; Y_{\text {exp }, 4}^{\max }=1.15 ; Y_{\text {exp }, 5}^{\max }=1.10 ;$ $Y_{\text {exp, } 6}^{\max }=1.12 ; Y_{\text {exp, } 7}^{\max }=1.06 ; Y_{\text {exp, } 8}^{\max }=1.00$. For degrees of freedom $v=7$ and confidence level $\alpha=0.05, \mathrm{t}_{\text {crit. }}=2.365$ (Student's table). Since $\mathrm{t}_{\text {calc. }}=0.535<\mathrm{t}_{\text {crit. }}$, there was no statistically significant difference between $Y_{\text {exp }}^{\max }$ and $Y_{\bmod }^{\max }$

A significant increase in levorin biosynthesis was detected with the optimised medium. The yield achieved was with $38 \%$ higher in comparison to the yield with the initial medium.

The dynamics of levorin biosynthesis by $S$. levoris $99 / 23$ with the optimised medium was modelled by means of a system of the following non-linear differential equations:

$$
\frac{d X(t)}{d t}=\mu(t) X(t)
$$

$$
\begin{aligned}
& \frac{d S(t)}{d t}=-\frac{1}{Y_{1}} \frac{d X(t)}{d t}-Y_{2} X(t) \\
& \frac{d P(t)}{d t}=\alpha_{1} \frac{d X(t)}{d t}+\alpha_{2} X(t) \\
& \mu(t)=\mu_{m} \frac{S(t)}{k_{s}+S(t)}-\beta X(t)
\end{aligned}
$$

$X(t), S(t)$, and $P(t)$ are the biomass concentrations, substrate concentration, and levorin concentration respectively when the process operates in the periodic mode, $Y_{1}$ is an economic coefficient, $Y_{2}$ is related to the rate of substrate assimilation by the cells in a stationary phase of the process, $k_{s}$ is a saturation constant, $\mu_{m}$ is the maximum specific growth rate, $\beta$ is the decay coefficient, $\alpha_{1}$ is the coefficient of substrate transformation into a metabolism product, and $\alpha_{2}$ is levorin accumulation rate in the stationary phase of the process.

Using (7), the microbial population growth was modelled in the presence of substrate limitation - modified Verhulst law.

The experimental data were formed by using the mean value of the results from six parallel experiments on the process dynamics. The lag phase time $(24 \mathrm{~h})$ was excluded from the data set.

The kinetic constant values in the model were determined using an optimisation procedure minimising the following criterion:

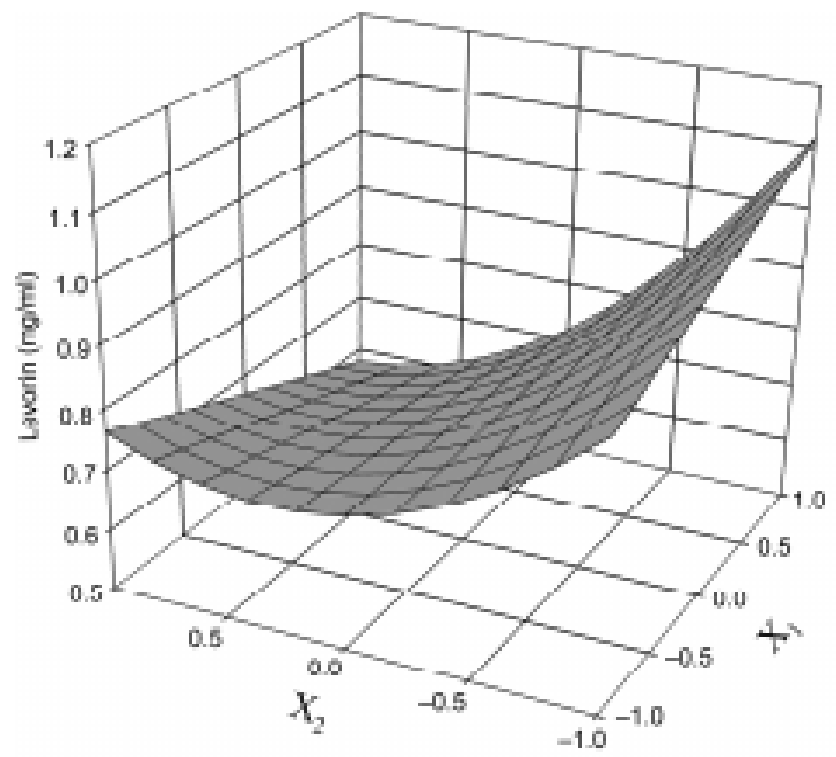

Fig. 1. $Y_{\bmod }=\mathrm{f}\left(\mathrm{X}_{1}, \mathrm{X}_{2}\right)$ at an optimum value of $\mathrm{X}_{3}$ and $\mathrm{X}_{4}+1$. 


$$
\begin{aligned}
J= & \sum_{i=1}^{n}\left[\left(X_{\text {exp }, i}-X_{\text {mod }, i}\right)^{2}+\left(S_{\text {exp }, i}-S_{\text {mod }, i}\right)^{2}+\right. \\
& \left.+\left(\mathrm{P}_{\exp , i}-\mathrm{P}_{\text {mod }, i}\right)^{2}\right] \rightarrow \min
\end{aligned}
$$

where exp, $i$ and mod, $i$ denote the process parameters according to the experimental data and models (4-7), and $n$ is the number of observations.

With this setup, the numerical values of the kinetic constants for the model were determined to be as follows:

$$
\begin{aligned}
& \mu_{m}=0.05583 \mathrm{~h}^{-1} ; k_{s}=0.97 \mathrm{mg} / \mathrm{ml} ; \\
& \beta=0.01054 \mathrm{ml} / \mathrm{mg} . \mathrm{h} ; Y_{1}=0.233 ; \\
& Y_{2}=0.0077 \mathrm{~h}^{-1} ; \alpha_{1}=0.169 ; \alpha_{2}=0.00117 \mathrm{~h}^{-1}
\end{aligned}
$$

The process dynamics is presented graphically in Fig. 2, Fig. 3 and Fig. 4. There was a good coincidence between the experimental and model results. $P(t)$ reached a maximum equal to $1.08 \mathrm{mg} / \mathrm{ml}$ at $t=131.5 \mathrm{~h}$ (Fig. 4). This value was obtained after approximation of the analytically calculated $P(t)$ data according to (6), with a second-order spline function and maximisation of $P(t)$, within the 108-144 $\mathrm{h}$ time interval and degree of freedom $t$. No check of the experiment reproduci-

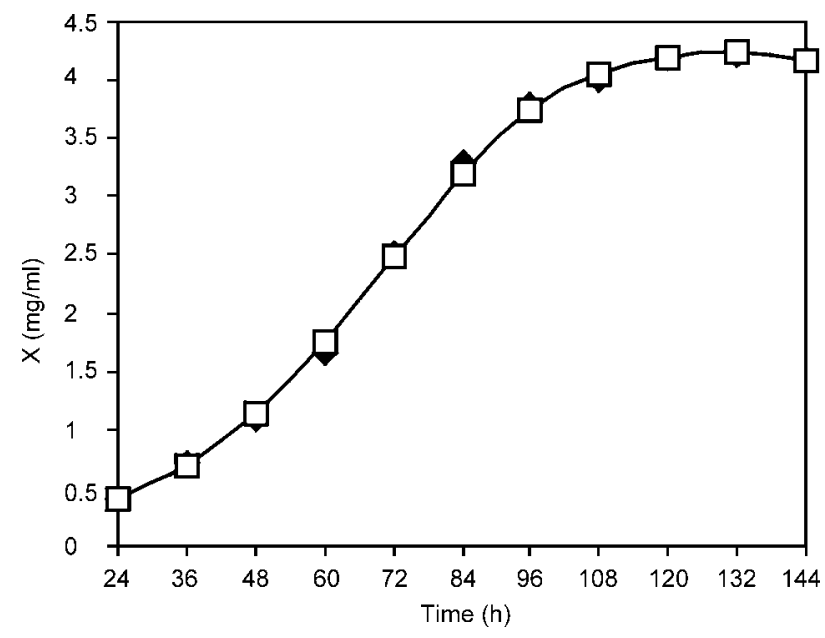

Fig. 2. Growth dynamics of S. levoris 99/23:

$(\diamond)$ experimental data; $(\square)$ model data.

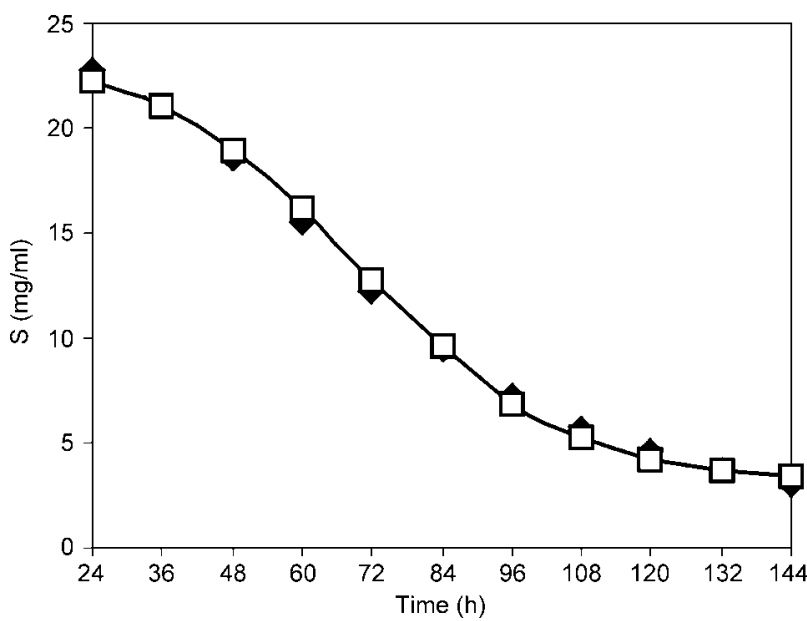

Fig. 3. Dynamics of substrate assimilation by $S$. levoris $99 / 23$ : $(\diamond)$ experimental data; $(\square)$ model data

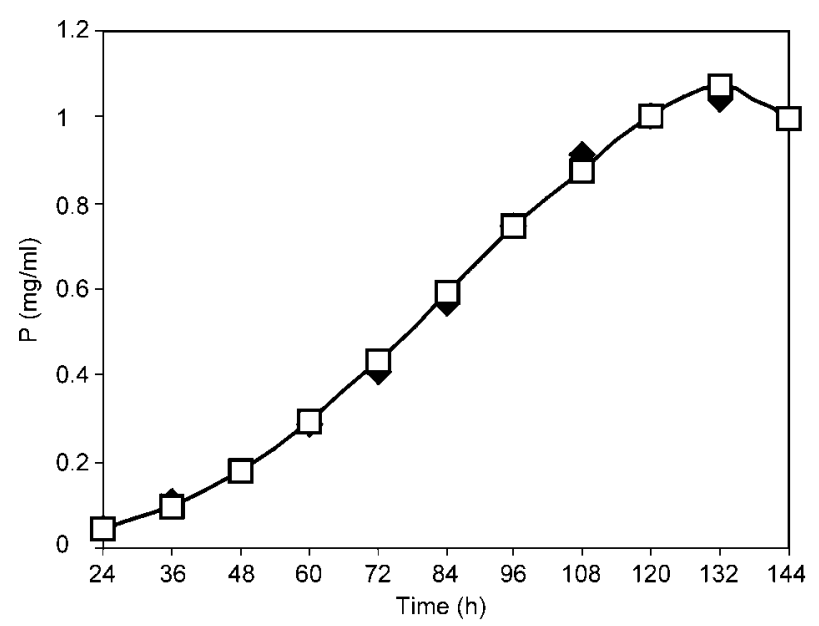

Fig. 4. Dynamics of levorin biosynthesis by S. levoris 99/23: $(\diamond)$ experimental data; $(\square)$ model data.

bility was run since it generally coincided with that of the studies on the process statics.

The kinetic constants can be interpreted in the following manner in a biotechnological aspect.

Under the experimental conditions, the value of decay coefficient $\beta$, was 5.3 fold lower than the value of $\mu_{m}$. At time point $t=131.5 \mathrm{~h}$, the available biomass exceeded the initial biomass by 10.7 folds.

Over $23 \%$ of the substrate was assimilated for biomass accumulation $\left(Y_{1}\right)$, and around $18.5 \%$ was used for maintaining the life activity in the stationary phase of the process. Since the values mentioned were close, it could be considered that approximately the same substrate amount was spent for both purposes.

The main antibiotic quantity was synthesised in the process stationary phase, and it was 6 fold higher than the value in the exponential phase, at a priori specified stationary phase duration of $36 \mathrm{~h}$.

The ratio $\alpha_{1} /\left(\alpha_{2} \cdot \Delta t\right)$ for $\Delta t=36 \mathrm{~h}$, in the stationary phase was 1:6. This came as another proof that levorin biosynthesis took place mainly at this stage of the microbial population growth.

At the end of the process, over $15.6 \%$ of the substrate remained unassimilated (Fig. 3). This was an indication for the presence of a critical value in respect to $S_{0}$ at which, the function would reach its maximum along with the complete substrate utilisation. Such an effect was not registered under the conditions of the experiment.

The material balance of the process came to the following considerations. The substrate consumption for biomass accumulation in the exponential growth phase of $S$. levoris $99 / 23$ was about $23.3 \%$, and the value for life activity during the process stationary phase was about $18.5 \%$. About $15.6 \%$ of the substrate was unassimilated at the end of the biotechnological process. For antibiotic synthesis in the exponential growth phase about $16.9 \%$ of the substrate was used, and the corresponding value for the stationary phase 
was $27.7 \%$. Total carbon source consumption was determined to be $102 \%$.

We consider that the results obtained provide an objective idea of the material balance in the system taking into account the subjective, methodological and instrumental error in the experimental data analysis.

The dynamics model of the levorin biosynthesis by $S$. levoris $99 / 23$ was valid. It described in detail even the lysis processes at the end of the stationary phase. In proof of this statement, the experimentmodel error dispersion values are presented for all observation points as follows: $\sigma_{\mathrm{x}}^{2}=0.0025 ; \sigma_{\mathrm{s}}^{2}=0.26$; $\sigma^{2}=0.0005$. The main share in criterion (8) is mainly attributed to $S$ since its natural values are 100 and more times higher than those of $X$ and $P$.

Conclusion. As a result of the optimisation of the nutrient medium for levorin biosynthesis by $S$. levoris 99/23 using mathematical modelling methods, the optimal composition of the medium was determined. The yield achieved with this medium was $38 \%$ higher in comparison to the initial one.

The dynamics of the antibiotic biosynthesis by S. levoris $99 / 23$ was studied by means of a non-linear differential equation system. The kinetic constant values were calculated for Verhulst model, describing the presence of substrate limitation. A valid model of the dynamics of levorin biosynthesis by S. levoris $99 / 23$ was obtained and the material balance of the process was assayed.

\section{Literature}

Belousova I.I., E.B. Lishnevskaya and R.E. Elgat and I.M. Tereshin. 1970. Effect of mineral phosphorus on the formation of levorin and fatty acids by Actinomyces levoris Krass, Antibiotics 15: 224-228.

Bob T.G., G.B. Barabanshchikova, V.Y. Raigorodskaya, E.D. Etingov, T.A. Fradkova, N.B. Kishkurno, V.M. Orekhova and A.F. Aleshkova. 1978. Differential spectrophotometric method of levorin analysis in culture broth and mycelium. Antibiotics 23: 882-885.

Bolshakova L.O., Y.D. Shenin, T.A. Fradkova, O.B. Ermolova, L.N. Astanina and V.M. Grigoryeva. 1989. Determination the biological activity of levorin by the international standard of candicidin. Antibiot. Chemother. 34: 732-736.

Gochev V., L. Kozuharova and M. Diltcheva. 2002. Optimisation of synthetic culture medium composition for levorin biosynthesis by Streptomyces levoris 99/23, Proceedings of the Tenth Congress of the Bulgarian Microbiologists 2002. Plovdiv, 2:105-108.

Jakovleva E.P. 1980. Synthetic medium for biosynthesis of polyenic antibiotics levorin and amphotericin B. Antibiotics 25 : 817-821.

Koleva B., V. Stanchev, D. Spasova and S. Bahchevanska. 2005. Investigation of the maceration process of Sofora japonica flowers. Sci. Works UFT, LII: 380-385.

Kozhuharova L. and V. Gochev. 2002. Selection of a highly active levorin producer strain. Science Conference with International Participation for Food, Health, Longevity - 2002". Smolyan 2002, 159-164.

Kozhuharova L., V. Gochev and L. Koleva. 2008. Isolation, purification and characterization of levorin produced by Streptomyces levoris 99/23. World J. Microbiol. Biotechnol. 24: 1-5.

Mason R., R. Gunst and J. Hess. 2003. Statistical design and analysis of experiments with applications to engineering and science. John Wiley \& Sons.

Mathews J. and K. Fink. 2001. Numerical methods using Matlab. Prentice Hall, Upper Saddle River, NJ.

Miller G.L. 1959. Use of dinitrosalicylic acid reagent for determination of reducing sugar. Anal. Chem. 31: 426-428.

The Software Eureka. 2000. Manual for Users.

Xian-Fa J., X. Jun-Ja, Zhu-Qiang and L. Guo-Yong. 2000. Model construction of the lycomycin fermentation process based on neural networks for identification. J. Luoyang Inst. Technol. 21: $85-88$. 